\title{
Group-based mobile learning: Do group size and sharing mobile devices matter?
}

\author{
Javier Melero, Davinia Hernández-Leo, Kalpani Manatunga \\ Universitat Pompeu Fabra, Barcelona, Spain \\ \{javier.melero, davinia.hernandez, kalpani.manatunga\}@upf.edu
}

\begin{abstract}
Within the field of Game-based Learning (GBL) location-based games are based on pervasive and mobile learning to allow the creation of in situ learning activities considering gamification mechanisms. In these learning activities collaboration often plays an important role. Usually, groups of students have to perform different tasks with single mobile device. This paper studies the effects of sharing a mobile device within groups and the size of groups in students' engagement and their activity performance in an indoor location-based learning activity. In particular, the paper focuses on a game designed by a secondary education teacher to support a learning activity in a contemporary art museum. The teacher's design has been implemented using "QuesTInSitu: The Game" technology. A total of 76 students played the game during a 3-hour activity in the museum. The analysis of the data shows that while there are not important differences in the satisfaction with the activity of the students carrying and not carrying the mobile device within their groups, carrying the device does have a significant (positive) impact in their performance. Group size (4 vs. 5 members) does not seem to be a variable affecting individuals' performance but students in 4-member groups express higher levels of engagement.
\end{abstract}

Keywords: Game-based learning, mobile learning, location-based games, secondary education

\section{INTRODUCTION}

Mobile learning has become a research field of interest of practitioners in all phases of education to facilitate informal learning in formal contexts (Pachler, Bachmair, \& Cook, 2010). Key aspects of such interests are the growing significance of mobile devices in learners' everyday lives (Vinu, Sherimon, \& Krishnan, 2011), and the increasing portability of these technologies, as well as the reduction in their cost and services. Besides, the use of mobile technology in education facilitates contextualized learning (Avouris \& Yiannoutsou, 2012), leading to a new educational paradigm in which students can learn anytime and anywhere (Jones \& Jo, 2004; Vinu et al., 2011). Considering the research domain of Gamebased Learning, mobile learning brings the possibility of creating location-based games (Davis, 2002; Jeng, Wu, Huang, Tan, \& Yang, 2010).

Educational location-based games rely on technological resources described as pervasive and ubiquitous computing, bringing possibilities to: enrich learning experiences by extending the learning beyond traditional classrooms and interacting with physical items by adding virtual layers of information; create fruitful learning experiences that involve exploration and cooperation (Hwang, Tsai, \& Yang, 2008); access to contextualized information, communication, analysis and interrelation of real place (Roschelle, 2003); entertain and stimulate (Cabrera et al., 2005; Davis, 2002); and be effective in terms of increasing the motivation to learn and to acquire a deeper understanding of concepts (Yatani, Onuma, Sugimoto, \& Kusunoki, 2004). 
Within the literature we can find several examples on the use of location-based games for learning purposes. Alien Contact! (Dunleavy, Dede, \& Mitchell, 2009) is intended to teach math, language arts, and scientific literacy skills. The mobile city game called Frequency 1550 (Huizenga, Admiraal, Akkerman, \& ten Dam, 2009) helps students playfully acquire historical knowledge of medieval Amsterdam. Blåtannkoden (Ceipidor, Medaglia, Perrone, De Marsico, \& Di Romano, 2009) involves solving different riddles related to the topics of a museum of telecommunications. Kurio (Wakkary et al., 2009) aims to engage family members to find historical information while visiting a museum. In Mad City Mystery (Squire \& Jan, 2007) middle school students investigate an untimely death caused by murder, suicide or the combination of several interacting toxic chemicals that are commonly found in the region. UbiCicero (Ghiani, Paterno, Santoro, \& Spano, 2007) proposes activities, such as quizzes, association games, memory games related to artworks of a museum. In Reliving the Revolution (Schrier, 2006) players try to find out who fired the first shot at the Battle of Lexington aiming to teach historical thinking and inquiry skill. Mystery in the Museum (Cabrera et al., 2005) provides a set of puzzle activities for a museum with cultural and historical educational content. In the game Savannah (Facer et al., 2004), children interact outdoors with a virtual Savannah and explore the opportunities and risks of being lions. Musex (Yatani et al., 2004) to solve different questions related to the science museum's exhibits by pairs of students. In Environmental Detectives (Klopfer, Squire, \& Jenkins, 2002), students investigate a simulated chemical spill on a college campus.

All these previous examples show a diverse variety of location-based games for outdoors and indoors. As we can see, these games can address different learning purposes (e.g.: science, math, or history) and be implemented for diverse types of handheld devices (e.g.: PDAs, tangible computing devices, or mobile phones). Besides, these games are mainly characterised by students cooperating or playing collaboratively while sharing the same mobile device. In particular, group-internal collaboration (i.e. several participants working as a group and collaborating by using a handheld device) is the most common approach implemented in these educational contexts. However, still further research is needed on evaluating the impact of mobile technologies in group-based activities in which collaboration often plays an important role (Hsu \& Ching, 2013). Besides, one of the key aspects that deserve further research is group size (Strijbos, Martens, \& Jochems, 2004). In particular, group size can have an effect on both students' influence on other members of the group and on students' performance (Cress, Kimmerle, \& Hesse, 2009; Schwabe, Göth, \& Frohberg, 2005)

This paper aims to bring more insights on the effects of using shared devices by students to play location-based learning games. In particular, the paper describes a location-based learning game in which students have to play in groups and share a mobile device while visiting a contemporary museum. The aim of this paper is twofold: first, to evaluate whether there is a difference between carrying versus not carrying the mobile device to intreact with the application within their groups. And secondly, an analysis focused on whether the group formation (in terms of number of students per group) also has an impact on students' engagement and on their activity performance.

Therefore, the remainder of this paper is structured as follows. Section 2 describes the design and implementation of the location-based learning game. Then, the methodology followed to evaluate the two focus of interest is presented in Section 3. The results of such evaluation are reported in Section 4. Next, Section 5 discusses the obtained results. And finally, Section 6 presents the main conclusions including future research directions, as well. 


\section{DESIGN OF MOBILE APPLICATION}

A secondary school art teacher designed a location-based learning game to be played in a contemporary art museum (see Table 1).

Table 1. Summary of the teacher design

\begin{tabular}{l|l}
\hline \multicolumn{1}{c|}{ Design elements } & \multicolumn{1}{c}{ MNAC Case } \\
\hline Number Levels & 3 levels (one per museum's room) \\
\hline Number Questions & 15 questions \\
\hline Scores for Correct Answers & 60 scores more \\
\hline Scores for Incorrect Answers & 20 scores less \\
\hline Number of Hints & 14 hints \\
\hline Scores Hints & 10 scores less \\
\hline Extra Bonus & 50 scores more \\
\hline Hints Content & Short text about the context related to the question \\
\hline Levels Information & Short sentence about the museum's room \\
\hline Feedback Messages & Informal \\
\hline
\end{tabular}

The teacher used a metaphor based on "puzzle board games" (Melero, Hernández-Leo, \& Blat, 2014) in order to design the mobile application. In particular, the resulted design consists of 3 levels (one level per museum's room) containing a total of 15 located questions. Some of the questions include hints, containing additional textual information, to help students find correct answers (see Table 2). Besides, the teacher also specified positive and negative amounts of scores associated to right and wrong answers. Finally, students are rewarded with extra bonus scores when all the questions for a particular level (i.e. room) are correctly answered.

Table 2. Example of the designed questions and hints

\begin{tabular}{l|l|l}
\hline Examples & \multicolumn{1}{|c}{ Question content } & \multicolumn{1}{c}{ Associated hint } \\
\hline \multirow{2}{*}{ Example 1 } & $\begin{array}{l}\text { "Santa Maria d'Aneu": In this } \\
\text { picture we can see two } \\
\text { seraphim with wings. These } \\
\text { contain eyes that symbolize } \\
\text { that God sees everything. } \\
\text { What are the seraphim doing? }\end{array}$ & $\begin{array}{l}\text { Seraphim, according to Catholic theology, are } \\
\text { spirits or angels of love, light and fire that } \\
\text { surround the throne of God. According to The } \\
\text { Bible, the prophet Isaiah saw seraphim in a } \\
\text { vision. Seraphim also represent purity and, in } \\
\text { the celestial hierarchy, they take up the } \\
\text { supreme position }\end{array}$ \\
\hline \multirow{5}{*}{ Example } & $\begin{array}{l}\text { Altarpiece of Santa Barbara: } \\
\text { What do the distinctive } \\
\text { attributes of Santa Barbara } \\
\text { symbolize in this altarpiece? }\end{array}$ & $\begin{array}{l}\text { Barbara was the daughter of Dioscor. Dioscor } \\
\text { lock her up in a tower. Barbara refused } \\
\text { marriage proposed by his father. Then, Barbara } \\
\text { was tortured and beheaded by her own father. } \\
\text { As punishment, lightning killed him }\end{array}$ \\
\hline
\end{tabular}

The designed activity was deployed by the "QuesTInSitu: The Game", a mobile application compliant to a conceptual model proposed by (Melero \& Hernández-Leo, 2014) based on computer-supported puzzle board games. "QuesTInSitu: The Game" interprets a game described according to the XML binding of the proposed conceptual model. In this particular case, the mobile application (see Figure 1) works as follows. First, students using the application have to go to the specific located places where the questions are placed in order to solve them. Somehow similarly to jigsaw puzzles, each located question (associated to the museum's exhibits) can be solved as many times as necessary until reaching the correct solution. Positive and negative scores reflect the correct and wrong answers by the 
students, and hints can be accessed if the students need some kind of help to solve the questions. The game finishes when the students have answered all the questions.

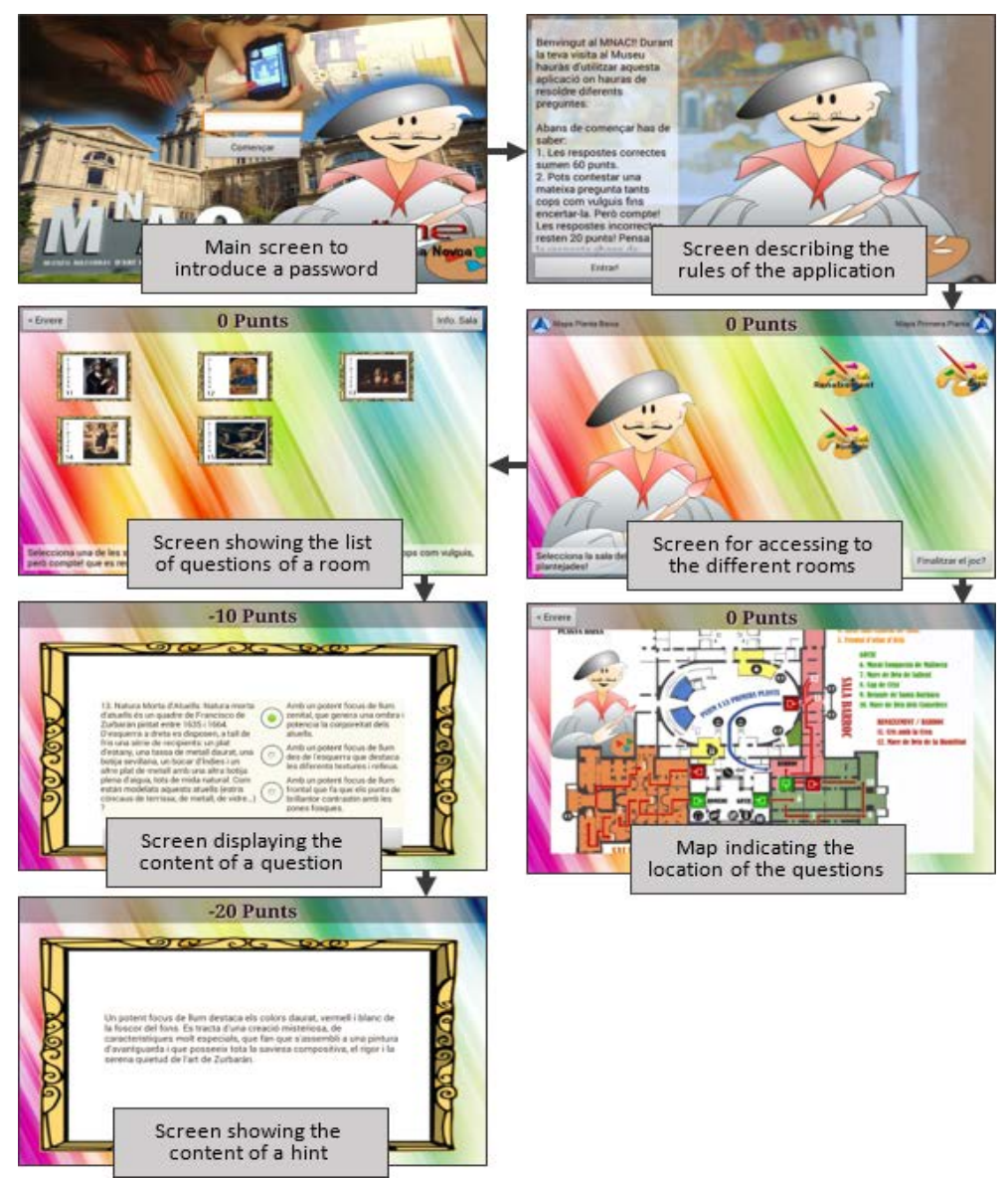

Figure 1. Screenshots of the implemented location-based learning game

Next section describes the methodology followed to evaluate the use of the implemented mobile application with secondary education students.

\section{METHODOLOGY}

Originally, 82 secondary education students (girls and boys between 14 and 16 years old) were expected to participate in the experiment. In order to set the students' groups, we asked the students to fill a form indicating the technical features of their Smartphones. After analysing the answers, Smartphones of 20 students met the requirements of the mobile application (Android application with, at least, version 2.3.3). Therefore, the students had to form 20 groups, considering that the owner of the Smartphone was the responsible of carrying the mobile phone during the activity. As a result, the following groups were made: 5 groups of 5 students, 13 groups of 4 students, 1 group of 3 students, and 1 group of 2 students. Finally, 76 students (divided in 19 groups) participated in the experiment. The resulting group formation was: 5 groups of 5 students, 11 groups of 4 students, 2 groups of 3 students, and 1 group of 1 student.

Before starting the activity, the students checked that the mobile application was working properly. Then, during the activity two researchers were following some groups of students and taking notes about their behaviour. Once the activity was finalized, students were requested to answer a questionnaire formed by 15 Likert-scale questions (response options: 
strongly agree, agree, neutral, disagree, and strongly disagree) and a post-test containing 6 questions from the mobile application. In particular, the questions were the following:

1. I liked performing the activity with a Smartphone.

2. I liked the way that the game content was designed (i.e. questions, scores, hints).

3. I checked that the person carrying the Smartphone correctly select the answers on the mobile application.

4. I trusted, without looking at the Smartphone's screen, the person correctly select the answers agreed by the people of the group.

5. I didn't look at the Smartphone's screen at all because the person carrying the device read aloud the questions.

6. During the whole activity, I was looking at the information displayed on the mobile application.

7. During the activity I was distracted while, at the same time, the person carrying the Smartphone was answering the questions.

8. I would have liked that the application indicated which person had to answer specific questions.

9. I would have liked that everyone in the group had the opportunity to use the mobile application.

10. All members of the group discussed the possible correct answers for each question.

11. We selected the answers to each question only if all members of the group agreed on the answer.

12. All members of the group participated in answering the questions.

13. The questions were answered by only some members of the group.

14. Sometimes, the person carrying the Smartphone answered the questions without the consent of the group.

15. The person carrying the Smartphone was the only one paying attention to the questions; the others were distracted.

Table 3 lists the different data sources: a) Likert-scale questionnaire to evaluate the students' opinions about the activity and collaboration between their peers, c) a post-test containing 6 questions from the mobile application, and b) direct observations from two researchers during the activity. A mixed evaluation method (Cairns \& Cox, 2008) has been followed considering the data gathering techniques. Besides, the obtained qualitative and quantitative data have been contrasted and triangulated (Guba, 1981). Quantitative data, obtained from the ratings given by the students in the questionnaires, are supported or rejected by the qualitative data, obtained from direct observations and students opinions.

Table 3. List of data gathering techniques

\begin{tabular}{|l|l|}
\hline \multicolumn{1}{|c|}{ Data source } & \multicolumn{1}{c|}{ Gathered data } \\
\hline Questionnaires [quest-X], & $\begin{array}{l}\text { Quantitative answers by students to Likert-scale questions } \\
\text { about their perception of their own behaviour during the } \\
\text { activity. } \\
\text { student, from } 1 \text { to } 76\end{array}$ \\
\hline $\begin{array}{l}\text { Post-questionnaires [post-Y], } \\
\text { providing positive and negative aspects of the activity. }\end{array}$ \\
$\begin{array}{l}\text { where } \mathrm{Y} \text { is the number assigned to a } \\
\text { student, from } 1 \text { to } 76\end{array}$ & $\begin{array}{l}\text { Quantitative answers by students to some multiple-choice } \\
\text { questions previously answered with the mobile application } \\
\text { during the activity. }\end{array}$ \\
$\begin{array}{l}\text { Observations [obs-Z], } \\
\text { where } Z \text { is the number assigned to a } \\
\text { researcher, from } 1 \text { to } 2\end{array}$ & $\begin{array}{l}\text { Direct observations taken by researchers during the } \\
\text { activity. }\end{array}$ \\
\hline
\end{tabular}


The following section reports the results (normalized to 100) obtained from the data gathered from different data sources.

\section{RESULTS}

The results obtained in this study are analysed considering two different perspectives: a) the use of the Smartphone (i.e. students carrying the Smartphone vs. students not carrying it within their group); and b) the number of students per group.

\subsection{Results on use of the Smartphone}

First, we analysed the results by comparing the students that were carrying the Smartphones within their group (19/76) with the rest of students (57/76). Figure 2 shows the results obtained (and normalized) for the different questions of the questionnaire.

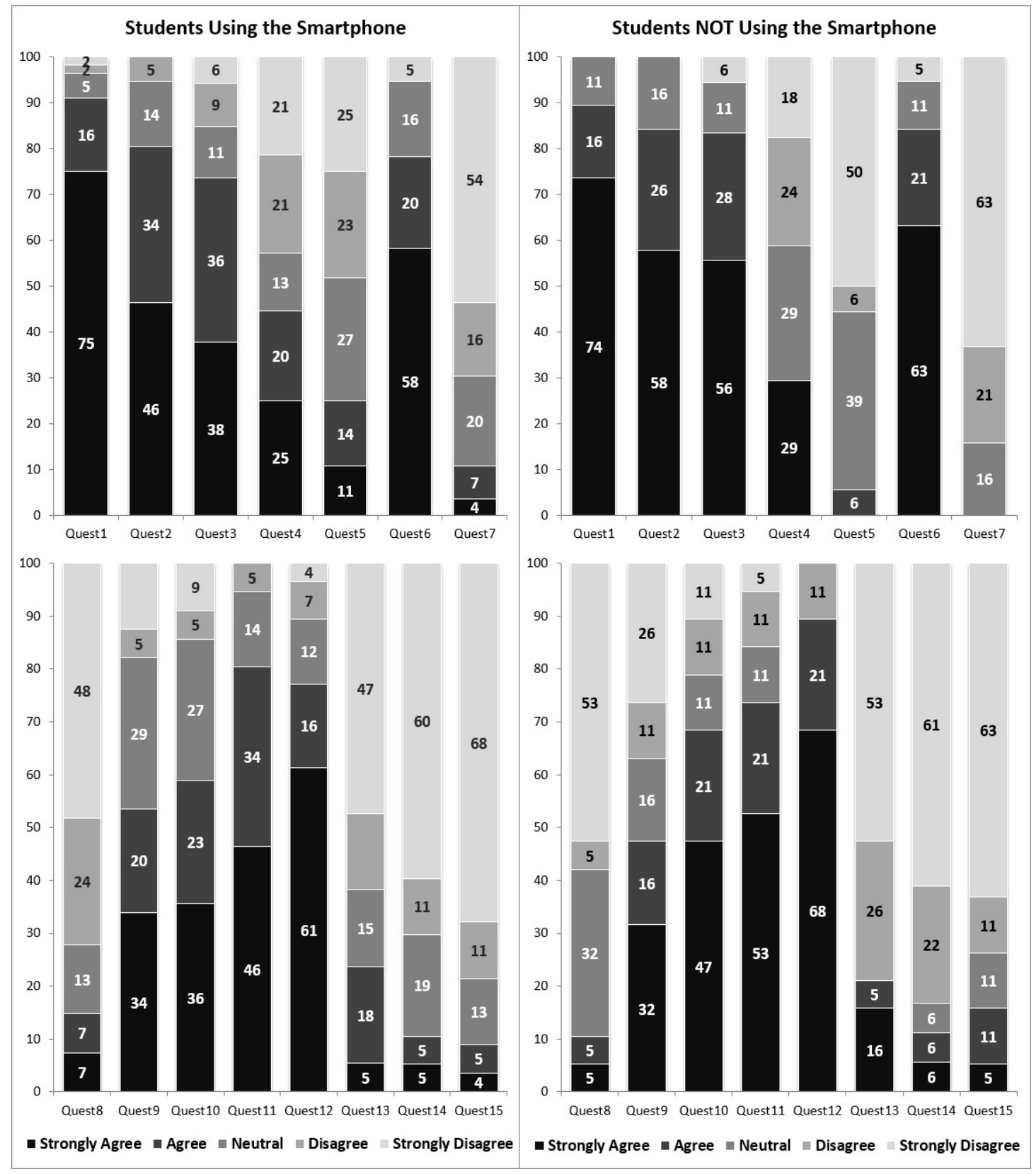

Figure 2. Results on the use of the Smartphone 
In general, students enjoyed performing the activity with the Smartphone as a group (question 1) and how the game content was designed (question 2). In fact, several students using the smartphone [quest-5-10-18-22-30-35-43-47-55-63] and not using it [quest-3-4-711-19-20-21-28-31-32-33-40-41-46-48-50-54-60-61-65] specifically indicated that they enjoyed the activity. Furthermore, paying attention to the students' participation, most of the students, in both cases, agreed that they participated and discussed the possible answers (questions 10-15). In fact, some students highlighted working in groups [quest-8-3234-35-37-63-75] and discussing the possible correct answers [quest-34] [obs-1-2].

Most of the students (using and not using the Smartphones) agreed that they would have liked that everyone used the mobile application (question 9). For instance, some students not using the mobile phone indicated that "I would like to suggest that all the members of the group could use the Smartphone" [quest-12], and "I would enjoy more the activity if everybody could use the mobile application" [quest-58]. Interestingly, some students in the two conditions (using [quest-2] and not using [quest-59] the Smartphones) indicated that they "were bored". However, in both cases, most of the students did not agree about the interest of an implementation of the game that indicates at every moment which person had to answer specific questions (question 8).

Slight differences are observed when comparing students' distractions. Specifically, more students not using the Smartphones ( $11 \%$ more than the students using the Smartphones) totally agreed or agreed that they were distracted (question 7). Following comments support this results: "Two members of the group were distracted while the other two were performing the activity" [quest-67], "Sometimes, I was distracted" [quest-17], and "The most exciting thing was to see one of our friends falling down" [quest-25-26].

Finally, in order to gain more insights regarding the impact of carrying or not carrying the Smartphones, we compared the students' marks obtained in a post-test. To this end, we carried out an independent two-sample t-test considering unequal sample sizes and unequal variances. Results (see Table 4) indicate that there is a significant difference between students using and not using the Smartphones. Therefore, the use of the Smartphones has an impact on students' activity performance.

Table 4. Results on an independent two-sample t-test

(Students using Smartphones vs. students not using Smartphones)

\begin{tabular}{|l|c|c|c|c|}
\hline \multicolumn{1}{|c|}{ Group Statistics } \\
\hline \multicolumn{1}{|c|}{ Groups } & N & Mean & Std. Deviation & Std. Error Mean \\
\hline $\begin{array}{l}\text { Students using } \\
\text { Smartphones }\end{array}$ & 19 & 5,11 &, 875 &, 201 \\
\hline $\begin{array}{l}\text { Students not using } \\
\text { Smartphones }\end{array}$ & 57 & 4,47 & 1,477 &, 196 \\
\hline
\end{tabular}

\begin{tabular}{|c|c|c|c|c|c|c|}
\hline \multicolumn{9}{|c|}{ T-Test for independent samples and unequal variances } \\
\hline & & & & \multicolumn{2}{|c|}{$\mathbf{9 5 \%}$ Confidence Interval of the } \\
t & df & Sig. & Mean & Std. Error & \multicolumn{2}{|c|}{ Difference } \\
\cline { 5 - 7 } & (2-tailed) & Difference & Difference & Lower & Upper \\
\hline 2,253 & 53,042 &, $\mathbf{0 2 8}$ &, 632 &, 280 &, 069 & 1,194 \\
\hline
\end{tabular}

Overall, results suggest a trend indicating that students using the Smartphones were more engaged and less distracted than the other students. Besides, the students interacting with the mobile application obtained significantly better learning outcomes than the rest of students. 


\subsection{Results on the number of students per group}

We also evaluate the same aspects from the perspective of the number of students per group (see Figure 3, containing the results normalized). The final aim is to analyse whether the group formation has an impact on students' opinions and performance. In particular, we compared the results from the groups of 5 students (25/76) with the groups of 4 students (44/76).



Figure 3. Results comparing 5-member groups vs. 4-member groups

On the one hand, when comparing groups of 5 students with groups of 4 students, following differences can be observed. More students from groups of 5 (14\% more compared to groups of 4 students) agreed that the person carrying the Smartphone answered the questions without the consent of the group (question 14). Also, 14\% of the students from 
groups of 5 agreed that the person carrying the Smartphone was the only one paying attention to the questions, while no students from groups of 4 agreed on that (question 15). Also, while no students of groups of 4 totally agreed that during the activity they were distracted, $5 \%$ of students of groups of 5 totally agreed on that (question 7).

On the other hand, when comparing the results, we obtained that more students from groups of 4 (compared with students from groups of 5) strongly agreed that: a) they (22\% more) like performing the activity (question 1$)$, b) they (26\% more) like how the game content was designed (question 2), c) they ( $20 \%$ more) were looking at the information displayed in the Smartphone (question 6) and d) they (12\% more) checked that the person carrying the Smartphone correctly selected the answers (question 3). In fact, [obs-1] observed that "two students started deviating from the activity", and [obs-2] stated "The girls are more focused on the activity than the boys. One of them (Student4) is 'playing' all the time not paying attention to the activity and moving around the rooms disconnected to the group. He is not participating in the activity at all". Both comments refer to 2 groups of 5 students. Moreover, more students from groups of 4 strongly agreed that all the members participated in the questions (question 12), and the answers were selected only if all members of the group agreed with that (question 11).

Furthermore, the groups of less than 4 students were not considered in the comparison because the number of students per group (only 2 groups of 3 students and 1 group of 1 student). However, we analyzed data from the 6 students of 3-member groups to also motivate the discussion of this paper (see Figure 4). In particular, relevant data were that all 6 students strongly agreed that they like performing the activity. More than a half of these students (4/6) also strongly agreed that they checked that: a) the person carrying the Smartphone correctly selected the answers (question 1), b) all the members participated in the questions (question 12), and c) the answers were selected only if all members of the group agreed with that (question 11). Besides, half of the students strongly disagreed that the person carrying the Smartphone was the only one paying attention to the questions (question 15), and that the application should indicate which person have to answer specific questions (question 8).

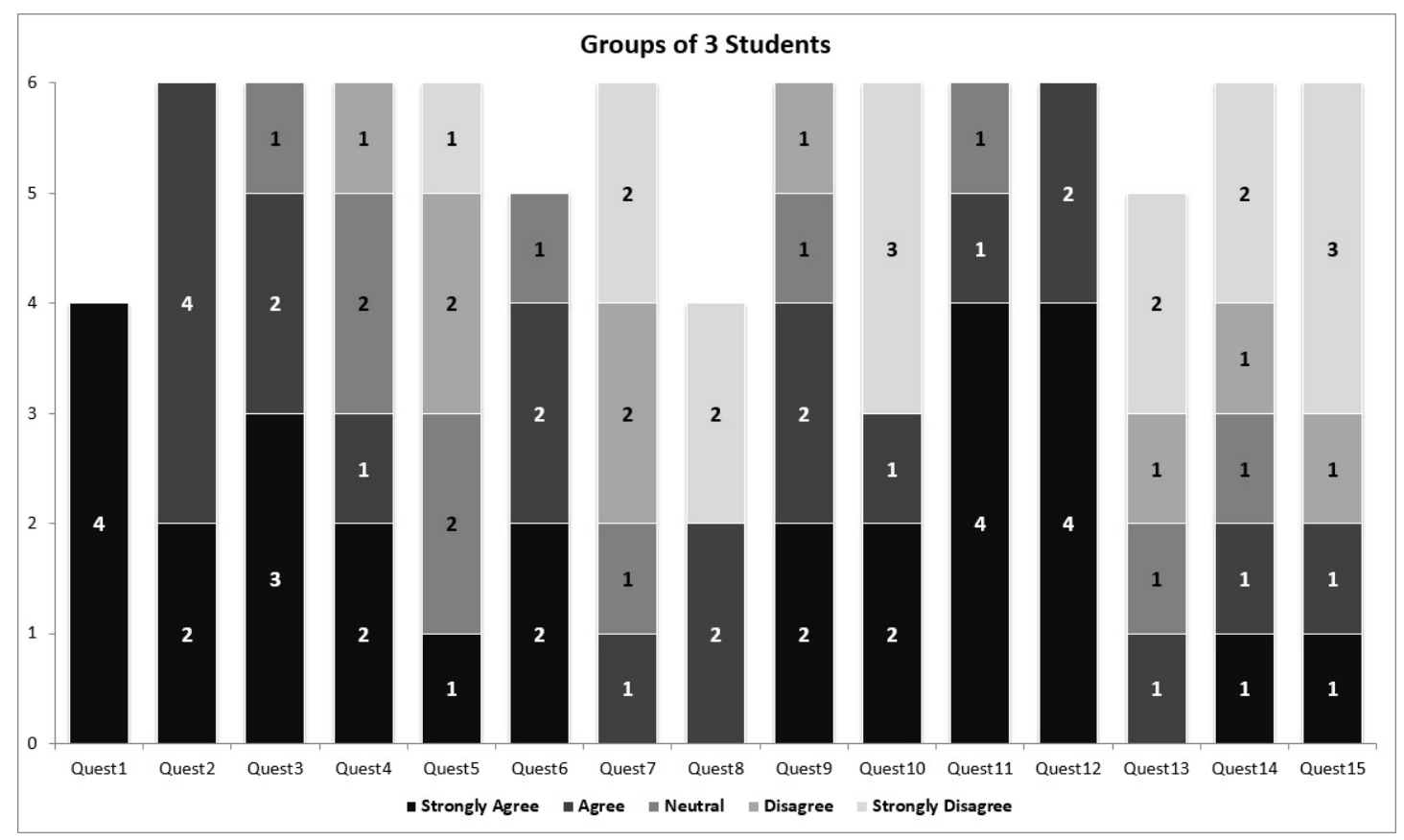

Figure 4. Results of 3-member groups 
We also carried out an independent two-sample t-test considering unequal sample sizes and unequal variances to compare students from groups of 5 with students from groups of 4 . Results, in this particular case, show that no statistical significance have been found when comparing both groups (see Table 5).

Table 5. Results on an independent two-sample t-test

(Students from groups of 5 vs. students from groups of 4)

\begin{tabular}{|l|c|c|c|c|}
\hline \multicolumn{1}{|c|}{ Groups } & N & Mean & Std. Deviation & Std. Error Mean \\
\hline $\begin{array}{l}\text { Students from groups } \\
\text { of 5 members }\end{array}$ & 25 & 4,80 & 1,472 &, 294 \\
\hline $\begin{array}{l}\text { Students from groups } \\
\text { of 4 members }\end{array}$ & 44 & 4,68 & 1,308 &, 197 \\
\hline
\end{tabular}

\begin{tabular}{|c|c|c|c|c|c|c|}
\hline \multicolumn{9}{|c|}{ t-test for independent samples and unequal variances } \\
\hline & & & & \multicolumn{2}{|c|}{$\mathbf{9 5 \%}$ Confidence Interval of the } \\
t & df & Sig. & Mean & Std. Error & \multicolumn{2}{|c|}{ Difference } \\
\cline { 5 - 7 } & $(\mathbf{2 - t a i l e d )}$ & Difference & Difference & Lower & Upper \\
\hline ,334 & 45,274 &, 740 &, 118 &, 354 &,- 595 &, 832 \\
\hline
\end{tabular}

Summarizing, the results suggest that the amount of students per group can have an influence on students' engagement. In smaller groups, students pay more attention to the information of the Smartphone, are less distracted and are more concerned about selected answers being correct. However, no statistical difference on students' activity performance was found when comparing groups of 4 students with groups of 5 students.

\section{DISCUSSION}

The results from this study suggest that group size and the role of being the student carrying the Smartphone can have an impact on students' attention and participation in group-based mobile learning activities. In general, all the students engaged and actively participated during the activity. Yet, students in 3-member groups expressed to have enjoyed activity more than 4-member groups. Similarly, students in 4-member groups appreciated the activity more than students in 5-member groups. Thus, the designed mobile learning application and the associated proposed activity seem to be more suitable for small groups. These results are aligned with the evidences reported by Schwabe et al. (2005), who also found significant differences in terms of both fun and immersion experience when comparing teams of two with teams of four in a mobile activity designed to support the orientation days at a university. Both studies indicate that smaller groups enjoy more this type of learning activities.

Furthermore, students carrying (and directly interacting with) the Smartphones seem to be more focused on the activity. Students interacting with the mobile application were clearly more engaged and concentrated. While students carrying the Smartphone were responsible of mobile interaction and answering questions, others participated in discussions of possible answers. However, as indicated in Schwabe et al. (2005): "The larger the team size becomes the more social activities dominate and the less visible is the technology and the game". This study provides additional evidences, in a different context, activity and with different group sizes, supporting the trend pointed by Schwabe et al. Our observations show that the level of participation in the discussions (by students not carrying the device) varied significantly depending on the groups and their sizes. The answers provided by the students (from groups of 3, 4, and 5 members) indicate that the larger is the group size, the lesser is the 
concentration level of students in the activity since they are more distracted and less participative in the agreement of answers. These insights suggest that the interest of conducting additional studies to analyze the impact of using one device per student compared to sharing a device per group.

Similarly, further research is still needed to explore whether scaffolding students with more structured collaborative techniques (e.g. collaborative learning flow patterns, distribution of roles, etc.) could engage them more during the activity, in terms of motivation and attention. Albeit the students do not generally prefer these approaches (question 8), our hypothesis is that having structured group dynamics (e.g., stablished rotation to carry the device) become more relevant in cases which number of students per group is higher.

\section{CONCLUSIONS}

Most of location-based learning game settings involve groups of students sharing devices to complete specific tasks. This paper has evaluated a real educational context of secondary education students playing a location-based learning game in a contemporary art museum. Considering the results obtained from the evaluation we can conclude that the mobile application, as it is currently designed, is especially suitable for small groups of students when the objective is to keep all the members focused on the activity. However, if groups of students are larger the mobile application or/and the activity supported by the application, should be redesigned to better support the attention and focused participation of students. Concerning this issue, results have shown that students would enjoy the activity more if everyone could use the mobile application at a certain time of the activity.

Furthermore, carrying the mobile devices and interacting with the mobile application have significant positive impact on students' activity performance. Students are more engaged and focused when interacting with the mobile application. As a consequence, they have higher chances of obtaining better learning outcomes.

Further research lines derived from this study involve identifying and proposing meaningful approaches in location-based learning games that foster collaboration between students. In this type of learning activities, providing students with concrete tasks or introducing collaborative techniques could be relevant for fostering engagement and improving students' activity performance.

\section{ACKNOWLEDGMENT}

This research has been partially funded by the Spanish Ministry of Economy and Competitiveness in the EEE Project (TIN2011-28308-C03-03). The authors would also like to thank Cristina Novoa, the teacher of the Escola Salesiana Mare de Déu dels Dolors in Sant Boi del Llobregat (Barcelona).

\section{REFERENCES}

Avouris, N., \& Yiannoutsou, N. (2012). A review of mobile location-based games for learning across physical and virtual spaces. Journal of Universal Computer Science, 18(15), 2120-2142.

Cabrera, J. S., Frutos, H. M., Stoica, A. G., Avouris, N., Dimitriadis, Y., Fiotakis, G., \& Liveri, K. D. (2005). Mystery in the Museum: Collaborative learning activities using handheld 
devices. In Proceedings of the 7th International Conference on Human Computer Interaction with Mobile Devices and Services (pp. 315-318). Salzburg, Austria.

Cairns, P., \& Cox, A. L. (2008). Research methods for human-computer interaction. NY, USA.

Ceipidor, U. B., Medaglia, C. M., Perrone, A., De Marsico, M., \& Di Romano, G. (2009). A museum mobile game for children using QR-Codes. In Proceedings of the 8th International Conference on Interaction Design and Children (pp. 282-283). Como, Italy.

Cress, U., Kimmerle, J., \& Hesse, F. W. (2009). Impact of temporal extension, synchronicity, and group size on computer-supported information exchange. Computers in Human Behavior, 25(3), 731-737.

Davis, S. M. (2002). Research to industry. Four years of observations in classrooms using a network of handheld devices. In Proceedings of the IEEE International Workshop on Wireless and Mobile Technologies in Education (pp. 31-38). Växjö, Sweden.

Dunleavy, M., Dede, C., \& Mitchell, R. (2009). Affordances and limitations of immersive participatory augmented reality simulations for teaching and learning. Journal of Science Education and Technology, 18(1), 7-22.

Facer, K., Joiner, R., Stanton, D., Reid, J., Hull, R., \& Kirk, D. (2004). Savannah: mobile gaming and learning? Journal of Computer Assisted Learning, 20(6), 399-409.

Ghiani, G., Paterno, F., Santoro, C., \& Spano, D. (2007). Interactive games in multi-device environments to enhance the learning experience of museum visitors. ERCIM News, 37-41. Retrieved from http://ercim-news.ercim.eu/en71/special/interactive-games-toenhance-the-learning-experience-of-museum-visitors

Guba, E. G. (1981). Criteria for assessing the trustworthiness of naturalistic inquiries. Educational Communication and Technology, 29(2), 75-91.

Hsu, Y. C., \& Ching, Y. H. (2013). Mobile computer-supported collaborative learning: A review of experimental research. British Journal of Educational Technology, 44(5), E111-E114.

Huizenga, J., Admiraal, W., Akkerman, S., \& ten Dam, G. (2009). Mobile game-based learning in secondary education: engagement, motivation and learning in a mobile city game. Journal of Computer Assisted Learning, 25(4), 332-334.

Hwang, G., Tsai, C., \& Yang, S. J. H. (2008). Criteria, strategies and research issues of contextaware ubiquitous learning. Educational Technology \& Society, 11(2), 81-91.

Jeng, Y., Wu, T., Huang, Y., Tan, Q., \& Yang, S. J. H. (2010). The add-on impact of mobile applications in learning strategies: A review study. Educational Technology \& Society, 13(3), 3-11.

Jones, V., \& Jo, H. J. (2004). Ubiquitous learning environment: an adaptive teaching system using ubiquitous Technology. In Proceedings of the 21st ASCILITE Conference (pp. 468474). Perth, Western Australia.

Klopfer, E., Squire, K., \& Jenkins, H. (2002). Environmental Detectives: PDAs as a window into a virtual simulated world. In Proceedings of the International Workshop on Wireless and Mobile Technologies in Education (pp. 95-98). Växjö, Sweden.

Melero, J., \& Hernández-Leo, D. (2014). A model for the design of puzzle-based games including virtual and physical objects. Journal of Educational Technology \& Society, 17(3), pp. 192-207.

Melero, J., Hernández-Leo, D., \& Blat, J. (2014). Teachers can be involved in the design of gamified m-learning activities: the use of the puzzle metaphor. In Proceedings of the 6 th International Conference on Computer Supported Education (accepted). Barcelona, Spain.

Pachler, N., Bachmair, B., \& Cook, J. (2010). Mobile learning: structures, agency, practices (vol. 1). New York, Dordrecht, Heidelberg, London: Springer. 
Roschelle, J. (2003). Unlocking the learning value of wireless mobile devices. Journal Computer Assisted Learning, 19(3), 260-272.

Schrier, K. (2006). Using augmented reality games to teach 21st century skills. In Proceedings of the ACM SIGGRAPH (pp. 1-8). Boston, Massachusetts, USA.

Schwabe, G., Göth, C., \& Frohberg, D. (2005). Does Team Size Matter in Mobile Learning? In Proceedings of the International Conference on Mobile Business (pp. 227-234). Sydney, Australia.

Squire, K. D., \& Jan, M. (2007). Mad City Mystery: Developing scientific argumentation skills with a place-based augmented reality game on handheld computers. Journal of Science Education and Technology, 16(1), 5-29.

Strijbos, J. W., Martens, R. L., \& Jochems, W. M. G. (2004). Designing for interaction: Six steps to designing computer-supported group-based learning. Computers \& Education, 42(4), 403-424.

Vinu, P. V., Sherimon, P. C., \& Krishnan, R. (2011). Towards pervasive mobile learning - the vision of 21st century. In Proceedings of the 3rd World Conference on Educational Sciences (pp. 3067-3073). Istanbul, Turkey.

Wakkary, R., Hatala, M., Muise, K., Tanenbaum, K., Corness, G., Mohabbati, B., \& Budd, J. (2009). Kurio: a museum guide for families. In Proceedings of the Third International Conference on Tangible and Embedded Interaction (pp. 215-222). Regent, UK.

Yatani, K., Onuma, M., Sugimoto, M., \& Kusunoki, F. (2004). Musex: A system for supporting children's collaborative learning in a museum with PDAs. Systems and Computers in Japan, 35(14), 773-782. 